\title{
Properties of Polyhydroxyalkanoate Granules and Bioemulsifiers from Pseudomonas sp. and Burkholderia sp. Isolates Growing on Glucose
}

\author{
Laís Postai Sacco $^{1}$ - Tereza Cristina Luque Castellane ${ }^{1}$. \\ Erica Mendes Lopes ${ }^{1}$. \\ Eliana Gertrudes de Macedo Lemos ${ }^{1}$. \\ Lúcia Maria Carareto Alves ${ }^{1}$
}

Received: 24 February 2015 / Accepted: 8 November 2015 /

Published online: 17 November 2015

(C) Springer Science+Business Media New York 2015

\begin{abstract}
A Burkholderia and Pseudomonas species designated as AB4 and AS1, respectively, were isolated from soil containing decomposing straw or sugar cane bagasse collected from Brazil. This study sought to evaluate the capacities of culture media, cell-free medium, and crude lysate preparations (containing PHB inclusion bodies) from bacterial cell cultures to stabilize emulsions with several hydrophobic compounds. Four conditions showed good production of bioemulsifiers (E24 $\geq 50 \%$ ), headed by substantially cell-free media from bacterial cell cultures in which bacterial isolates from Burkholderia sp. strain AB4 and Pseudomonas sp. strain AS1 were grown. Our results revealed that the both isolates (AB4 and AS1 strains) exhibited high emulsification indices (indicating usefulness in bioremediation) and good stabilities.
\end{abstract}

Keywords Bioemulsifier - Biopolymers $\cdot$ Burkholderia sp. Emulsifying activity Polyhydroxybutyrate $\cdot$ Pseudomonas sp.

\section{Introduction}

Biosurfactants were first discovered as extracellular compounds resulting from bacterial fermentation, and they have clearly defined hydrophilic and hydrophobic groups [1]. In the

Tereza Cristina Luque Castellane teluque@yahoo.com.br

Lúcia Maria Carareto Alves lmcalves@fcav.unesp.br

1 Departamento de Tecnologia, Faculdade de Ciências Agrárias e Veterinárias, UNESP-Univ Estadual Paulista, Rod. Prof. Paulo Donato Castellane km 5, CEP 14884-900 Jaboticabal, SP, Brazil 
literature, the terms biosurfactant and bioemulsifier are considered interchangeable; however, although all bioemulsifiers are considered biosurfactants, not all of the biosurfactants produce stable emulsions [2]. These surface-active molecules reduce surface tension and interfacial tension in aqueous solutions and hydrophobic mixtures [2]. Their functional properties are diverse and include emulsification, de-emulsification, wetting, foaming, phase separation, surface activity, and reduction of the viscosity of crude oil. Thus, it is feasible to utilize such molecules for many applications in agriculture, food processing, the cosmetic and pharmaceutical industries [1], and especially in the oil industry [3], and as demulsifying agents [4].

Bioemulsifier molecules have recently received increasing attention due to their potential as an environmentally friendly alternative to chemically synthetic surfactants. The main reason for this is because bioemulsifiers exhibit advantages over synthetic counterparts that include reduced toxicity, increased biodegradability, better environmental compatibility, increased foaming, high selectivity, and high specific activity at extreme temperatures, $\mathrm{pHs}$, and salinities [5].

A number of high-molecular-weight bioemulsifiers are produced by microorganisms (i.e., bacteria, yeasts, and fungi). These bioemulsifiers are secreted extracellularly and have a wide range of exciting properties related to bioremediation. Microbial communities of Acinetobacter, Arthrobacter, Bacillus, Enterobacter, Halomonas, Pseudomonas, Rhizobium [6], Rhodococcus, and yeast have been reported to produce bioemulsifier molecules as exopolysaccharides (EPSs) [7], poly- $\beta$-hydroxyalkanoates (PHA) and poly(3hydroxybutyrate) $[\mathrm{P}(3 \mathrm{HB})][8]$.

Microorganisms synthesize a wide variety of high- and low-molecular-mass bioemulsifiers [9]. The molecular structures of these molecules include chemical groups, such as phospholipids, lipoproteins or lipopeptides, lipopolysaccharides, lipoproteins, neutral lipids, glycolipids (e.g., rhamnolipids and glycoglycerolipids), proteins, amphipathic polysaccharides, and complex mixtures of these biopolymers and polymeric bioemulsifiers [10, 11]. The lowmolecular-weight lipopeptide compounds produced by microorganisms are an interesting class of amphiphilic membrane-active bioemulsifiers due to their manifold attractive surface properties and biological activities $[11,12]$.

A number of investigations in the literature have reported on the preparation of emulsions using different types of surfactants. There are numerous reports on the surfactant production of different species of the genera Pseudomonas and Burkholderia. The surfactants produced by these isolates can vary across species [4]. Additionally, many bacterial species are able to accumulate PHAs. Types of PHA, such as polyhydroxybutyrate (PHB), poly(hydroxybutyrateco-hydroxyvalerate) (PHBV), poly(hydroxybutyrate-co-hydroxyhexanoate) (PHBHHx), and polyhydroxyoctanoate $(\mathrm{PHO})$, are frequently studied in terms of potential biotechnological applications [13, 14]. The majority of PHA-producing Pseudomonas sp. can use different substrates, such as glycerol, mannitol, fructose, glucose, n-paraffins, and vegetable oils, to produce medium-chain-length PHAs (mclPHA) with C6 to C14 monomer units, and they are able to produce rhamnolipid-type biosurfactants [15]. Various reports indicate that rhamnolipids, trelalolipids, and sophorolipids are the best-known glycolipids produced by Pseudomonas. aeruginosa [16], and $\mathrm{P}(3 \mathrm{HB})$ is one of the best-characterized PHAs [17]. Soberón-Chavez et al. [18] described that the PHA metabolic pathways of $P$. aeruginosa and a bioemulsifier rhamnolipid are related by one of their precursors, i.e., the 3-hydroxyacids. Nevertheless, the relationship between PHA synthesis and bioemulsifier production has been only partially studied [19]. PHA as a bioemulsifiers exists in a purified and soluble form as inclusion bodies and cell lysates that impart emulsification abilities to various oils in water. There are amphiphilic proteins that undoubtedly play structural roles in the granule such that a 
barrier is created between the hydrophobic surface of the polymer and the surrounding hydrophilic cytoplasm [20]. Ma et al. [14] reported that the emulsification ability of PhaR is better than those of commonly used chemical surfactants.

As the presence of intracellular PHB granules and exopolymers is important for the emulsification of various hydrophobic substrates, the objective of this study was to evaluate the capacities of culture media, cell-free media, and crude lysate preparations (containing PHB inclusion bodies) from a bacterial cell culture to stabilize emulsions with several hydrophobic compounds.

\section{Materials and Methods}

\section{Microorganisms}

The bacteria used in this study were isolated from soil containing decomposing straw or sugar cane bagasse. These isolates were previously identified by sequence analyses of the $16 \mathrm{~S}$ ribosomal DNA (rDNA), and subsequent BlastN analyses indicated that the bacteria designated as AB4 that were isolated from the bagasse were classified as Burkholderia sp. (KP076213), and the bacteria designated as AS1 that were isolated from the soil were classified as Pseudomonas sp. (KP076214).

\section{Media and Growth Conditions}

For routine isolate growth and evaluations of emulsifying activities, the bacterial isolates were streaked in a PGYA medium containing glycerol $\left(10 \mathrm{~g} \mathrm{~L}^{-1}\right)$ as a carbon source and incubated for $24 \mathrm{~h}$ at $30^{\circ} \mathrm{C}$. After $24 \mathrm{~h}$, each inoculating strain was cultivated in a $250-\mathrm{mL}$ flask $(100 \mathrm{~mL}$ of medium in each) containing PGYL liquid medium on a rotary shaker at $150 \mathrm{rpm}$ for $24 \mathrm{~h}$. At this time, a suspension with an optical density at $600 \mathrm{~nm}\left(\mathrm{OD}_{600}\right)$ of 2.0 was obtained. The temperature was maintained at $30^{\circ} \mathrm{C}$. Aliquots of the corresponding cultures were transferred to $1000-\mathrm{mL}$ Erlenmeyer flasks containing $500 \mathrm{~mL}$ of modified half-liquid PSYL medium (registration PI0304053-4) containing glucose $\left(10 \mathrm{~g} \mathrm{~L}^{-1}\right)$ as a carbon source and incubated for $72 \mathrm{~h}$ at $150 \mathrm{rpm}$ and $30^{\circ} \mathrm{C}$.

\section{Morphological Characterization and Biopolymer Detection}

The plates containing glucose as a carbon source were used to qualitatively examine the production of biopolymers (EPS and PHA) and for morphological characterization. Briefly, diluted broth suspensions were spotted onto modified PSYL plates. These plates were incubated at $30{ }^{\circ} \mathrm{C}$ for $48 \mathrm{~h}$ before documentation. Next, the plates were soaked with Sudan Black solution $(0.03 \%$, diluted in $100 \%$ ethanol) for $10 \mathrm{~min}$. The excess dye was removed with $70 \%$ ethanol. Darker blue strains were further analyzed for PHA production. However, the mucoidy of the colonies and the biopolymer detections were performed visually. The colonies were visualized after and before soaking in a Sudan Black solution.

\section{Estimation of Biomass}

Cell growth was determined by measuring the optical densities of the samples, using a UVvisible spectrophotometer (Biophotometer, Eppendorf AG22331) at $600 \mathrm{~nm}$. At the final time 
of incubation, $10-\mathrm{mL}$ samples of culture broth were sterilely collected and centrifuged at $12,000 \mathrm{~g}$ for $20 \mathrm{~min}$. The biomass paste was washed three times with $0.85 \% \mathrm{w} / \mathrm{v}$ saline solution. The paste was dried by heating in a hot air oven set at $50{ }^{\circ} \mathrm{C}$ until a constant weight was attained while not allowing the cells to be charred.

\section{Emulsifying Activity}

The emulsification activity and stability studies were performed using the culture media and cell-free broths obtained from the centrifugation of the cultures at $12,000 \times \mathrm{g}$ for $40 \mathrm{~min}$. After centrifugation, the cell-free culture broth was cooled at $20{ }^{\circ} \mathrm{C}$, and the emulsification activity was then measured. The capacities of the culture media and substantially cell-free media from the bacterial cultures to stabilize the emulsions containing several hydrophobic compounds were tested as described by Lopes et al. [21]. Three milliliters of each hydrophobic compound was vigorously mixed with $2 \mathrm{~mL}$ of a cell-free supernatant or culture medium in a screw-top glass tube. The mixture was mixed vigorously for $2 \mathrm{~min}$ and allowed to stand for 24 or $168 \mathrm{~h}$ at room temperature. After $24 \mathrm{~h}$ or $168 \mathrm{~h}$, the height of the emulsion layer was measured. The tested compounds included hydrocarbons (hexane and diesel oil), paraffin liquid, and sunflower oils.

The emulsions were observed under a light microscope to determine the sizes and uniformities of the drops in the oil phase.

\section{Preparation of the PHB Inclusion Bodies from the Cell Lysates}

The cells were collected by centrifugation, and $20 \mathrm{ml}$ of pre-cooled, sterilized, and re-distilled water was added to suspend the precipitated biomass. After sonication (40\% equipment output), centrifugation $\left(4^{\circ} \mathrm{C}\right.$ and $12,000 \times g$ ) was conducted for $30 \mathrm{~min}$, and the supernatants and precipitates were collected. After 2-3 washes using pre-cooled and re-distilled water, the precipitates containing the polyhydroxybutyrate inclusion bodies were freeze-dried to obtain a powdered form of the PHB inclusion bodies. For the PHB that was obtained in pellet form, the samples were freeze-dried (Eppendorf Vacuum Concentrator Plus) and maintained at $-80{ }^{\circ} \mathrm{C}$ [14].

\section{Preparation of PHB Solution and Emulsification Studies}

Lyophilized PHB samples in pellet form from both isolates were dissolved in deionized water to form 3000,1500 , and $750 \mu \mathrm{g} \mathrm{mL}^{-1}$ soluble PHB inclusion body solutions. Two milliliters of each aqueous surfactant solution and $3.0 \mathrm{ml}$ of paraffin liquid or diesel oil were mixed together in cylindrical glass vials. The mixtures of oil and aqueous solutions were then treated by vortexing at maximum power for $60 \mathrm{~s}$. All samples were stored in a dark temperaturecontrolled room, and the emulsification values were measured after $24 \mathrm{~h}$.

\section{Calculation of the Emulsification Value and Stability Test}

The emulsification indices were measured using the following equation and are noted as $E_{24}$ and $E_{168}: E_{24}=(h e / h T) \times 100$, where $h e(\mathrm{~mm})$ is the height of the emulsion layer, and $h T(\mathrm{~mm})$ is the overall height of the mixture. The emulsifying activities are expressed as the percentages of the total height occupied by the emulsion. For each emulsification value, all experiments 
were performed at least in triplicate. A good bioemulsifier-producing isolate was designated as one that produced good emulsion stability $\left(E_{24} \geq 50 \%\right)$.

\section{Thermal Stability Study}

To determine the effects of temperature and heat treatment on the emulsifying activities, paraffin liquid oil was selected. Stability studies were undertaken using the culture medium. All emulsions were mixed with paraffin liquid oil (2:3, v/v ratio) and then mixed vigorously for $2 \mathrm{~min}$ and allowed to stand for $24 \mathrm{~h}$ at room temperature and $37^{\circ} \mathrm{C}$ in a BOD-type oven. After $24 \mathrm{~h}$, the emulsions were measured. Next, to study the effects of heat, the emulsions were heated in an autoclave to $121{ }^{\circ} \mathrm{C}$ for $20 \mathrm{~min}$ [21]. In all three conditions, the samples were allowed to stand at room temperature for $2 \mathrm{~h}$ after the respective treatments before the measurements of the emulsification indices were made for comparisons with the corresponding values obtained before the heat treatments.

\section{Results and Discussion}

\section{Detection of the Biopolymers and Morphological Comparisons Between Pseudomonas sp. and Burkholderia sp.}

After 24,48 , and $72 \mathrm{~h}$ of growth, based on the colony morphologies, we confirmed the differences between the isolates from Burkholderia sp. strain AB4 and Pseudomonas sp. strain AS1. On the modified solid medium PSYA with glucose, the surfaces of the AB4 colonies exhibited a dry matte appearance, while the surfaces of the AS1 isolate colonies were smooth and shiny (data not shown). The lipophilic SB staining showed that the AS1 strain produced a greater number of colonies that contained PHA and exhibited dark granules compared to the AB4 strain (data not shown). Therefore, the SB staining exhibited high sensitivity in PHA screening and is thus a simple and rapid method of screening strains for the presence of this biopolymer [22].

The growth curves of the bacteria (i.e., the AS1 and AB4 strains) revealed their abilities to liquid PSYL medium with glucose (Fig. 1). The lag phase of Pseudomonas sp. strain AS1 $(8 \mathrm{~h})$ was longer than that of Burkholderia sp. strain AB4 (6 h), and the stationary phase begins after more than $20 \mathrm{~h}$ of culture.

Previous tests using our testing conditions revealed that the maximum yields of PHB and fresh cells are observed at $72 \mathrm{~h}$ and that a plateau is subsequently attained. Moreover, cell lysis can lead to the enzymatic degradation of biopolymers (e.g., PHB and EPS) toward the late stages of the growth. Hence, an incubation time of $72 \mathrm{~h}$ was selected for this study.

The average $\mathrm{pH}$ and biomass values (fresh and dried) of the cultures at the end of the cultivation period $(72 \mathrm{~h}$ ) are shown in Fig. 2 and Table 1. The pHs of the culture supernatants were all in the acidic range between 5.58 and 6.60 . The cell dry weights were slightly greater for Pseudomonas sp. strain AS1.

Interestingly, the results of the present study were obtained following the cultivation of the bacteria in modified liquid PSYL medium with glucose, and we confirmed that the AB4 has the capacity to form biofilms in flasks (results not shown). Moreover, during growth in the liquid medium, we observed that these isolates did not produce viscous biopolymers such as exopolysaccharides. These isolates were unable to precipitate EPS via the mixing of alcohol 
Fig. 1 Growth curves of Burkholderia sp. strain AB4 (a) and Pseudomonas sp. strain AS1 (b) on the PSYL modified with glucose as a carbon source
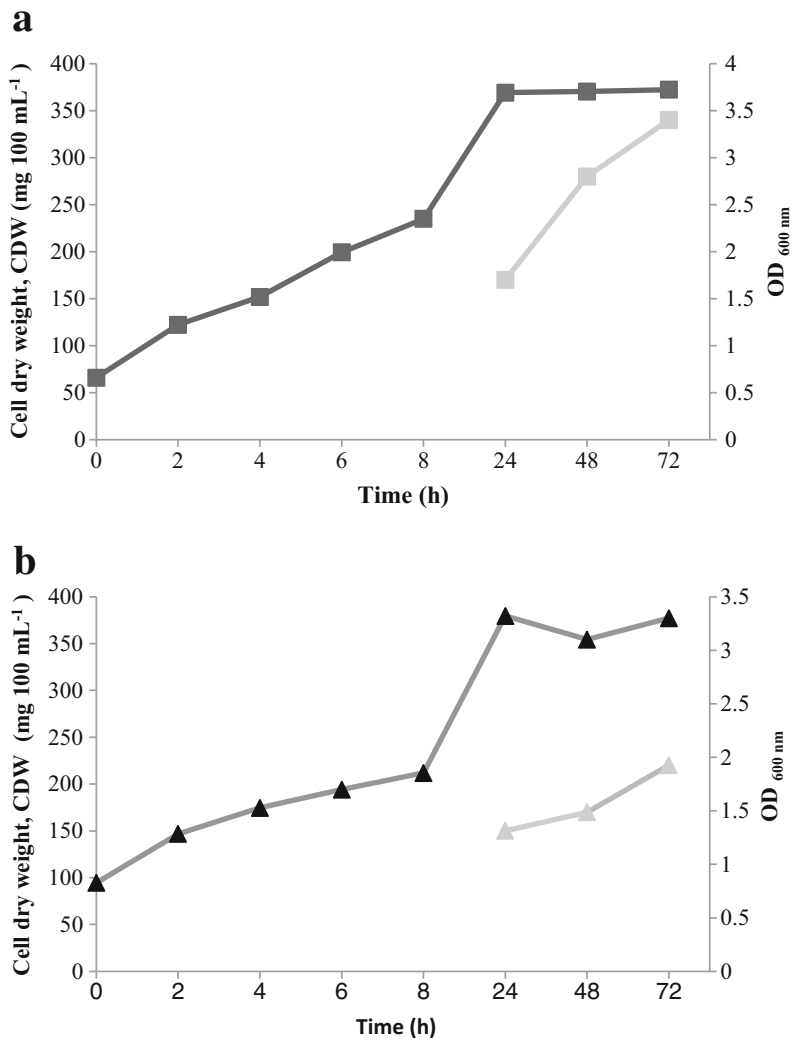

with a substantially cell-free medium from a bacterial cell culture. Published reports of the production of exopolymers have revealed that glucose does not seem to be a good carbon source for EPS production with several bacteria species [23, 24]. In contrast, our results disagree with one study [25] of EPS production by $P$. aeruginosa in cultures containing glucose. These researchers obtained ESP primarily by increasing the temperature from $20{ }^{\circ} \mathrm{C}$ to $30{ }^{\circ} \mathrm{C}$ and observed the greatest polymer production at $40{ }^{\circ} \mathrm{C}\left(372.4 \mathrm{mg} \mathrm{L}^{-1}\right)$ [25].

Fig. 2 Evaluations of the $\mathrm{pH}$ from cultures with glucose as the carbon source during the cultivation period

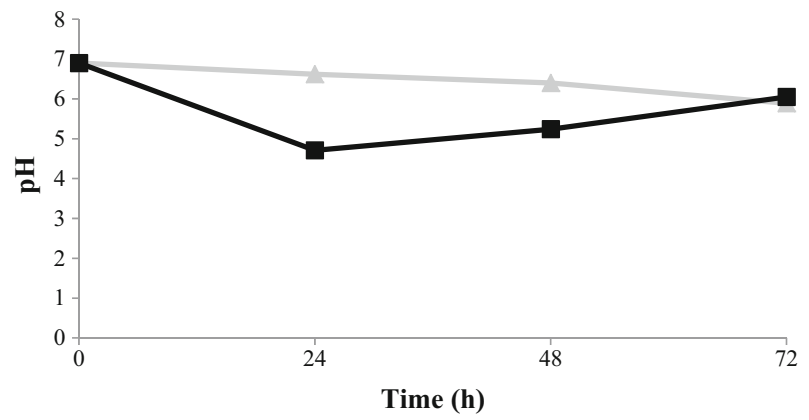

-Pseudomonas sp. strain AS1 $\quad \rightarrow$ Burkholderia sp. strain AB4 
Table 1 Evaluations of the $\mathrm{pH}$ and biomass (fresh and dried) of the cultures with glucose as the carbon source at the end of the cultivation period $(72 \mathrm{~h})$

\begin{tabular}{llllr}
\hline Species/Strains & $\begin{array}{l}\text { Cell fresh weight } \\
\mathrm{g} \mathrm{L}^{-1}\end{array}$ & $\begin{array}{l}\text { Cell dry weight } \\
\mathrm{g} \mathrm{L}^{-1}\end{array}$ & Initial $\mathrm{pH}$ & Final pH \\
\hline Burkholderia sp./AB4 & $8.62 \pm 0.15$ & $2.00 \pm 0.09$ & $6.9 \pm 0.01$ & $6.60 \pm 0.02$ \\
Pseudomonas sp./AS1 & $6.96 \pm 0.25$ & $2.50 \pm 0.013$ & $6.9 \pm 0.01$ & $5.58 \pm 0.11$
\end{tabular}

There is evidence that the synthesis of poly-3-hydroxybutyrate is inversely proportional to the syntheses of exopolysaccharides. However, Fernandes Júnior et al. [26] reported that in isolate 8.1c from the root of the pigeonpea [Cajanus cajan (L.) Millsp], the production of large quantities of EPS did not negatively affect the production and accumulation of PHB, allowing an increment in PHB accumulation reaching $49 \%$ in starch-supplemented medium for this isolate. In the present study, we observed only a high level of production of PHB by Pseudomonas sp. strain AS1 (data not shown).

\section{Emulsifying Potential}

Emulsification tests were conducted with diesel oil, hexane, paraffin liquid, and sunflower oils; the capacities for emulsification are shown in Table 2. The emulsifying activities of both of the culture media (i.e., with and without cells) in which Burkholderia sp. strain AB4 were grown formed consistent emulsions in which some the hydrophobic substrates after $24 \mathrm{~h}$ were paraffin oil, sunflower oil, and hexane.

Some emulsions did not exhibit stability. The E168 values were smaller than the E24 values when the cell-free media were used for emulsification, but the culture media was able to stabilize the emulsions with the three compounds. The diesel oil was not effectively emulsified. The Burkholderia sp. AB4 strain was also able to produce extracellular water-soluble bioemulsifiers during growth with glucose as a carbon source. This finding is in agreement with the reports of Anyanwy et al. [27] that the products are extracellular because the removal of the biomass does not affect the activity. Bento et al. [28] showed that no substantial emulsification is achieved with cell-free extracts, which indicates that the emulsification activity is not extracellular. Glazyrina et al. [29] reported that bioemulsifiers are present on the cell surface or excreted into the extracellular space.

The isolate of Pseudomonas sp. AS1 was unable to produce more extracellular watersoluble bioemulsifiers during growth with glucose as the carbon source. The culture cell isolates produced bioemulsifiers that resulted in $45,44,33$, and $13 \%$ indices $\left(E_{24}\right)$ with sunflower oil, hexane, paraffin liquid oil, and diesel, respectively, while the results here in obtained show that the bioemulsifier produced by the cell-free medium from this bacterial cell cultures and in the presence sunflower oil $\left(E_{24}=63 \%\right)$ possesses a high ability to stabilize emulsions with different hydrocarbons, thus representing a potential candidate to be used in a variety of biotechnological and industrial applications. However, the cell-free medium did not emulsify with other tested oils (Table 2). Most microbial surfactants are substrate specific and solubilize or emulsify different hydrocarbons at different rates [30] i.e., Emulsan does not emulsify pure aliphatic, aromatic, or cyclic hydrocarbons; however, mixtures of those compounds can be efficiently emulsified [31]. 
Table 2 Stabilities of the emulsifying activities of the culture media and substantially cell-free media from bacterial cell cultures in which bacterial isolates (from the AB4 and AS1 strains) were grown

\begin{tabular}{|c|c|c|c|c|c|}
\hline \multirow[t]{3}{*}{ Samples } & \multirow[t]{3}{*}{ Hydrocarbon/oil } & \multirow{2}{*}{\multicolumn{2}{|c|}{$\frac{\text { Cell-free medium }}{\text { Emulsifying index cell }(\%)^{\mathrm{a}}}$}} & \multicolumn{2}{|c|}{ Culture medium } \\
\hline & & & & & \\
\hline & & $E_{24}$ & $E_{168}$ & $E_{24}$ & $E_{168}$ \\
\hline \multirow[t]{4}{*}{ Burkholdheria sp. AB4 } & Paraffin oil & 53 & 34 & 43 & 34 \\
\hline & Sunflower oil & 55 & 47 & 52 & 52 \\
\hline & Diesel oil & 0.27 & - & 0.26 & 0.27 \\
\hline & Hexane & 36 & 21 & 45 & 43 \\
\hline \multirow[t]{4}{*}{ Pseudomonas sp. AS1 } & Paraffin oil & 1 & 1 & 33 & 26 \\
\hline & Sunflower oil & 63 & 45 & 45 & 42 \\
\hline & Diesel oil & 0.26 & - & 13 & 0.26 \\
\hline & Hexane & 0.27 & - & 44 & 44 \\
\hline
\end{tabular}

Values in italics: emulsifier index $\left(E_{24}\right)$ with values above $50 \%$

${ }^{a}$ The results are expressed as percentages of the total height occupied by the emulsion. The values of the means of at least three determinations

- oil not emulsified

The formation of an emulsion is also an indicator of the emulsifying properties of the isolated bioemulsifier [10]. The criteria for determining the emulsion-stabilizing capacity of an emulsifier consists of evaluating its ability to maintain at least $50 \%$ of the original emulsion volume $24 \mathrm{~h}$ after its formation [11]. Once the emulsification index is evaluated, this information can be used to estimate the appropriate amount of bioemulsifier required, e.g., for use in environmental pollution treatment plants.

Regarding other bioemulsifiers, the emulsification capacity of cell-free bacterial culture of Pseudomonas sp. strain AS1 was equal to that of the purified surfactant produced by B. subtilis PTCC 1696, which reaches an emulsification index of $64.4 \%$ [32] and to that of $C$. echinulate, which reaches a $65 \%$ index $\left(E_{24}\right)$ with soybean oil, as reported by Silva et al. in 2014 [33]. However, the AS1-produced extracellular bioemulsifier exhibited an emulsification capacity (63\%) that exceeded those of the bioemulsifiers from Bacillus cereus (48\%) [34] and Bacillus licheniformis MS3 (36\%) [35].

The stability of the emulsifier index is an important factor for the use of bioemulsifiers under specific environmental conditions [33]. Thermal stability studies of the bioemulsifier were performed by heating the cultures to $121^{\circ} \mathrm{C}$ for $20 \mathrm{~min}$ and cooling them to room temperature. Additionally, the emulsifier indices were also measured, and the emulsions were then allowed to stand for $24 \mathrm{~h}$ at $37{ }^{\circ} \mathrm{C}$. The heating caused significant effects on the bioemulsifier performances. Figure 3 shows that the emulsification activities were not stable following exposure to high temperatures $\left(37^{\circ} \mathrm{C}\right.$ or $\left.121{ }^{\circ} \mathrm{C}\right)$. A recent study revealed that samples are significantly different after sterilization, which indicates that high levels of thermal stability are not observed for the bioemulsifier from Bradyrhizobium elkanii strains [21]. In contrast, Ma et al. [14] identified a robust protein, termed PhaR stable, that was stable in temperatures as high as $95^{\circ} \mathrm{C}$ and exhibited emulsification values of 75 and $65 \%$ for diesel oil and soybean oil, respectively. These findings indicate the thermal stability of the structure and function of PhaR. In 2006, Sarubbo et al. [36] reported that the loss of emulsifying activity at 
$120{ }^{\circ} \mathrm{C}$ can be explained by the denaturation of the microbactan protein fraction during heating.

\section{Effect of PHB Body Concentrations and Mixing on Emulsification}

Emulsification tests with the PHB inclusion bodies were conducted with paraffin liquid oil. The emulsification capacities are shown in Fig. 4. When the PHB inclusion body concentrations reached 750 and $3000 \mu \mathrm{g} \mathrm{mL} \mathrm{m}^{-1}$, the emulsification values with the paraffin liquid oil were greater than $42 \%$ (Fig. 4). Ma et al. [14] reported that a small amount of PHB inclusion bodies can potentially be used to achieve optimal emulsification effects. However, compared to the concentrations of PHB inclusion bodies as a bioemulsifier, the emulsification capacity of $1500 \mu \mathrm{g} \mathrm{mL}^{-1}$ (emulsification indices of 14 and $20 \%$ ) was a lesser emulsification value than that of 750 and $3000 \mu \mathrm{g} \mathrm{mL}^{-1}$ for the concentrations of protein PHB inclusion bodies. Furthermore, the emulsions formed remained stable for one month at $30{ }^{\circ} \mathrm{C}$.

Additionally, we choose diesel oil for results comparison because it presented the lowest emulsification index values in the previous trials (Table 2). For comparison, the emulsification

Fig. 3 Effects of heat $\left(121^{\circ} \mathrm{C}\right)$ on the stabilities of the paraffin emulsification capacities of bacterial culture from Burkholderia sp. strain AB4 (black square) and Pseudomonas sp. strain AS1 (gray square). a Emulsifying activity at $30{ }^{\circ} \mathrm{C}$ of the non-treated sample compared with that of the autoclaved sample. b Emulsifying activity of the nontreated sample at $37{ }^{\circ} \mathrm{C}$ compared with that of the autoclaved sample. All data points are presented as the mean \pm the SD of three different experiments that were performed on different days (each experiment was conducted in triplicate) a

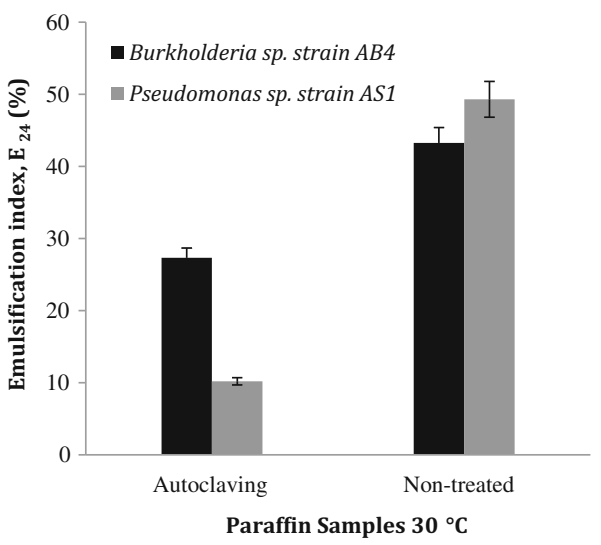

b

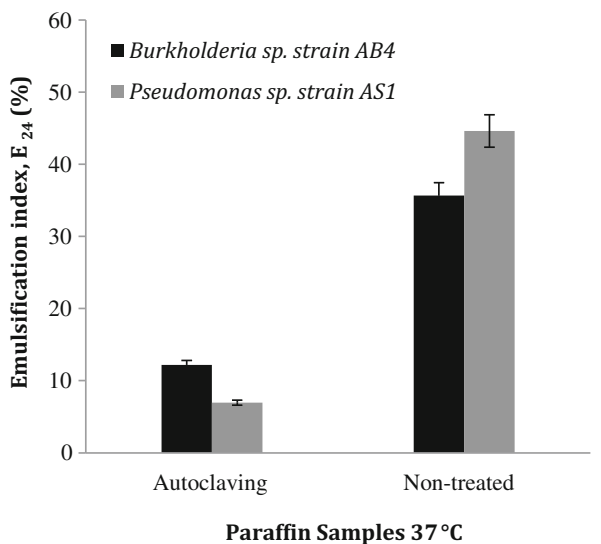


Fig. 4 Study of the emulsification abilities of PHB inclusion bodies as bioemulsifiers. Different concentrations of PHB inclusion bodies were used to emulsify liquid paraffin oil. a The concentrations of $\mathrm{PHB}$ inclusion bodies were 750,1500 , and $3000 \mu \mathrm{g} \mathrm{mL}^{-1}$. b The $750 \mu \mathrm{g} \mathrm{mL}^{-1}$ concentration of PHB inclusion bodies with diesel and paraffin

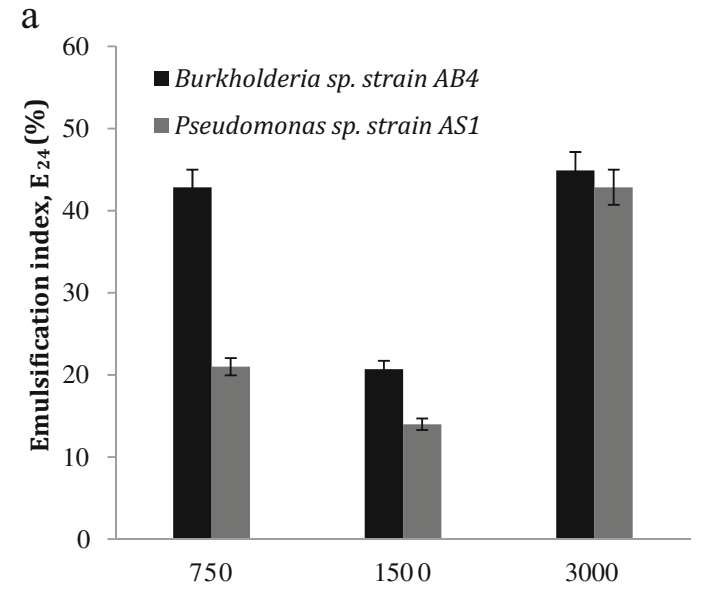

Concentration of PHB inclusion bodies with paraffin $\left(\mu \mathrm{g} \mathrm{mL}^{-1}\right)$

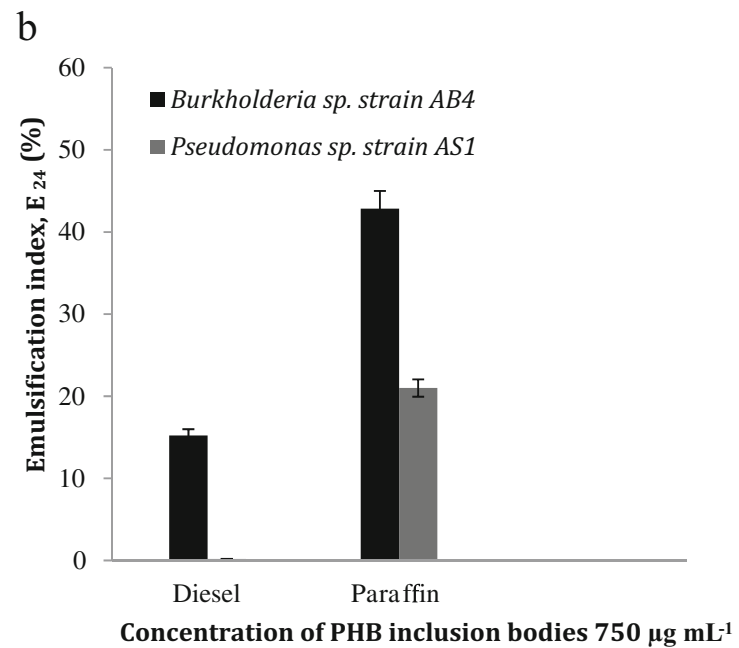

value between these PHB inclusion bodies and diesel oil was $15 \%$ when the concentration reached $750 \mu \mathrm{g} / \mathrm{ml}$, as produced by Burkholderia sp. AB4 (Fig. 4b), whereas this concentration reached $750 \mu \mathrm{g} / \mathrm{ml}$ when produced by the other strain (AS1) and not emulsified. It was possible to use the PHB inclusion bodies and cell lysates for their emulsification abilities for various oils in water, e.g., diesel and paraffin oils.

\section{Conclusions}

The emulsifying activities of the culture media and cell-free media in which Burkholderia sp. strain $\mathrm{AB} 4$ was grown formed consistent emulsions. While the finding of $E_{24}=63 \%$ for substantially cell-free media from bacterial cell cultures in which bacterial isolate from Pseudomonas sp. strain AS1 were grown is highly remarkable, since it is, as far as the authors 
know, the first report of surfactant production evidence by this species. The emulsification tests with the PHB inclusions elicited better results at concentrations of 750 and $3000 \mu \mathrm{g} \mathrm{mL}^{-1}$ for both strains (AS1 and AB4).

The findings of the present study contribute significantly to the applications of the use of small amounts of PHB inclusion bodies, and culture and cell-free media can potentially be used to achieve optimal emulsification effects in environmental biotechnology and bioremediation.

Acknowledgments The authors acknowledge the Program of Agricultural Microbiology FCAV/UNESP Campus Jaboticabal and Coordenação de Aperfeiçoamento de Pessoal de Nível Superior (CAPES) for providing a PROAP doctoral scholarship, Post-doctoral National Program (PNPD/CAPES), and Conselho Nacional de Desenvolvimento Científico e Tecnológico (CNPq) for the financial support.

\section{References}

1. Kitamoto, D., Morita, T., Fukuoka, T., Konishi, M., \& Imura, T. (2009). Self-assembling properties of glycolipid biosurfactants and their potential applications. Current Opinion in Colloid \& Interface Science, $14,315-328$.

2. Marchant, R., \& Banat, I. M. (2012). Biosurfactants: a sustainable replacement for chemical surfactants? Biotechnology Letters, 34, 1597-1605.

3. Marti, M. E., Colonna, W. J., Patra, P., Zhang, H., Green, C., Reznik, G., Pynn, M., Jarrell, K., Nyman, J. A., Somasundaran, P., Glatz, C. E., \& Lamsal, B. P. (2014). Production and characterization of microbial biosurfactants for potential use in oil spill remediation. Enzyme and Microbial Technology, 55, 31-39.

4. Xia, W. J., Li, Y., Wang, P., Xiu, J. L., \& Dong, H. P. (2012). Characterization of a ther- mophilic and halotolerant Geobacillus pallidus $\mathrm{H} 9$ and its application in microbial enhanced oil recovery (MEOR). Annals of Microbiology, 62, 1779-1789.

5. Abouseoud, M., Maachi, R., Amrane, A., Boudergua, S., \& Nabi, A. (2008). Evaluation of different carbon and nitrogen sources in production of biosurfactant by Pseudomonas fluorescens. Desalination, 223, 143151.

6. Castellane, T. C. L., Persona, M. R., Campanharo, J. C., \& Lemos, E. G. M. (2015). Production of exopolysaccharide from rhizobia with potential biotechnological and bioremediation applications. International Journal of Biological Macromolecules, 74, 515-522.

7. Satpute, S. K., Banat, I. M., Dhakephalkar, P. K., Banpurkar, A. G., \& Chopade, B. A. (2010). Biosurfactants, bioemulsifiers and exopolysaccharides from marine microorganisms. Biotechnology Advances, 28, 436-450.

8. Bertrand, J. L., Ramsay, B. A., Ramsay, J. A., \& Chavarie, C. (1990). Biosynthesis of poly- $\beta$ hydroxyalkanoates from pentoses by Pseudomonas pseudoflava. Applied and Environmental Microbiology, 56, 3133-3138.

9. Rosenberg, E., \& Ron, E. Z. (1999). High- and low-molecular- mass microbial surfactants. Applied Microbiology and Biotechnology, 52, 154-162.

10. Whang, L. M., Liu, P. W. G., Ma, C. C., \& Cheng, S. S. (2008). Application of biosurfactants, rhamnolipid, and surfactin, for enhanced biodegration of diesel-contaminated water and soil. Journal of Hazardous Materials, 151, 155-163.

11. Willumsen, P. A. E., \& Karlson, U. (1997). Screening of bacteria, isolated from PAH-contaminated soils, for production of biosurfactant and bioemulsifiers. Biodegration, 7, 415-423.

12. Peypoux, F., Bonmatin, J. M., \& Wallach, J. (1999). Recent trends in the biochemistry of surfactin. Applied Microbiology and Biotechnology, 51, 553-563.

13. Chen, G. Q. (2009). A microbial polyhydroxyalkanoates (PHA) based bio and materials industry. Chemical Society Reviews, 38, 2434-2446.

14. Ma, H. G., Liu, M. M., Li, S. Y., Wu, Q., Chen, J. C., \& Chen, G. Q. (2013). Application of polyhidroxy alkanoate (PHA) synthesis regulatory protein $\mathrm{PhaR}$ as a bio-surfactant and bacterial agent. (2013). Journal of Biotechnology, 166, 34-41.

15. Boulton, C., Ratledge, C. (1987). In Biosurfactants and Biotechnology, ed. Kosaric, N., Cairns, W.L., Gray, N.C.C., Dekker, M. New York, 47-87. 
16. Robert, M., Mercade, M. E., Bosch, M. P., Parra, J. L., Espuny, M. J., Manresa, M. A., \& Guinea, J. (1989). Effect of the carbon source on biosurfactant production by Pseudomonas aeruginosa 44T. Biotechnology Letters, 11, 871-874.

17. Yang, J. E., Choi, Y. J., Lee, S. J., Kang, K. H., Lee, H., Oh, Y. H., Lee, S. H., Park, S. J., \& Lee, S. Y. (2014). Metabolic engineering of Escherichia coli for biosynthesis of poly (3-hidroxybutyrate-co-3-hidroxyvalerate) from glucose. Applied Microbiology and Biotechnology, 98, 95-104.

18. Soberón-Chavez, G., Le'pine, F., \& De'ziel, E. (2005). Production of rhamnolipids by Pseudomonas aeruginosa. Applied Microbiology and Biotechnology, 68, 718-725.

19. Di Martino, C., Catone, M. V., López, N. I., \& Iustman, L. J. R. (2014). polyhydroxyalkanoate synthesis affects biosurfactant production and cell attachment to hydrocarbons in Pseudomonas sp. KA-08. Current Microbiology, 68, 735-742.

20. Steinbüchel, A., Aerts, K., Liebergesell, M., Wieczorek, R., Babel, W., Föllner, C., Madkour, M. H., Mayer, F., Pieper-Fürst, U., Pries, A., \& Valentin, H. E. (1995). Considerations on the structure and biochemistry of bacterial polyhydroxy alkanoic acid inclusions. Canadian Journal of Microbiology, 41, 94-105.

21. Lopes, E. M., Castellane, T. C. L., Moretto, C., Lemos, E. G. M., \& Souza, J. A. M. (2014). Emulsification properties of bioemulsifiers produced by wild-type and mutant Bradyrhizobium elkani strains. Journal of Bioremediation \& Biodegradation, 5, 1-6.

22. Burdon, K. L. (1946). Fatty materials in bacteria and fungi revealed by staining dried, fixed slide preparation. Journal of Bacteriology, 52, 665-678.

23. Janczarek, M., \& Skorupska, A. (2009). Rhizobium leguminosarum bv. Trifoliiros R gene expression is regulated by catabolic repression. FEMS Microbiology Letters, 291, 112-119.

24. Velasco, S., Arskold, E., Paese, M., Grage, H., Irastorza, A., Radstrom, P., \& Van Niel, E. W. J. (2006). Environmental factors influencing growth of and exopolysaccharide formation by Pedicoccus parvulus 2.6. International Journal of Food Microbiology, 111, 252.

25. Killic, N. K., \& Donmez, G. (2008). Environmental conditions affecting exopolysaccharide production by Pseudomonas aeruginosa, Micrococcus sp., and Ochrobactrum sp. Journal of Hazardous Materials, 154, 1019-1024.

26. Fernandes Júnior, P. I., Oliveira, P. J., Rumjanek, N. G., \& Xavier, G. R. (2011). Poly- $\beta$-hydroxybutyrate and exopolysaccharide biosynthesis by bacterial isolates from pigeonpea [Cajanuscajan (L.) Millsp] root nodules. Applied Biochemistry and Biotechnology, 163, 473-484.

27. Anyanwu, \& Chukwudi, U. (2010). Surface activity of extracellular products of a Pseudomonas aeruginosa isolated from petroleum contaminated soil. International Journal of Environmental Sciences, 1, 225-235.

28. Bento, F. M., Camargo, F. A. O., Okeke, B. C., \& Frankenberger-Jr, W. T. (2005). Diversity of biosurfactant producing microorganisms isolated from soils contaminated with diesel oil. Microbiological Research, 160, $249-255$.

29. Glazyrina, J., Junne, S., Thiesen, P., Lunkenheimer, K., \& Goetz, P. (2008). In situ removal and purification of biosurfactants by automated surface enrichment. Applied Microbiology and Biotechnology, 81, $23-31$.

30. Illori, M. O., Amobi, C. J., \& Odocha, A. C. (2005). Factors affecting biosurfactant production by oil degradading Aeromonas spp. Isolated from a tropical environment. Chemosphere, 61, 985-992.

31. Navon-Venezia, S., Zosim, Z., Gottlieb, A., Legmann, R., Carmeli, S., Ron, E., et al. (1995). Alasan, a new bioemulsifier from Acinetobacter radioresistens. Applied and Environmental Microbiology, 61, 3240-3244.

32. Ghojavand, H., Vahabzadeh, F., Roayaei, E., \& Shahraki, A. K. (2008). Production and properties of a biosurfactant obtained from a member of the Bacillus subtilis group (PTCC 1696). Journal of Colloid and Interface Science, 342, 172-176.

33. Silva, N. R. A., Luna, M. A. C., Santiago, A. L. C. M. A., Franco, L. O., Silva, G. K. B., Souza, P. M., Okada, K., Albuquerque, C. D. C., Silva, C. A. A., \& Campos-Takaki, G. M. (2014). Biosurfactant and bioemulsifier produced by a promising Cunninghamella echinulata isolated from caatinga soil in the northeast of Brazil. International Journal of Molecular Sciences, 15, 15377-15395.

34. Velázquez-Aradillas, J. C., Toribio-Jiménez, J., del Carmen Ángeles González-Chávez, M., Bautista, F., Cebrián, M. E., Esparza-García, F. J., \& Rodríguez-Vázquez, R. (2011). Characterisation of a biosurfactant produced by a Bacillus cereus strain tolerant to cadmium and isolated from green coffee grain. World Journal of Microbiology and Biotechnology, 27, 907-913.

35. Biria, D., Maghsoudi, E., Roostaazad, R., Dadafarin, H., SahebghadamLotfi, A., \& Amoozegar, M. A. (2009). Purification and characterization of a novel biosurfactant produced by Bacillus licheniformis MS3. World Journal of Microbiology and Biotechnology, 26, 871-878.

36. Asfora Sarubbo, L., Moura De Luna, J., \& De Campos-Takaki, G. M. (2006). Production and stability studies of the bioemulsifier obtained from a new strain of Candida glabrata UCP 1002. Electronic Journal of Biotechnology, 9, 401-406. 